\title{
Ecological Adaptation and Speciation: The Evolutionary Significance of Habitat Avoidance as a Postzygotic Reproductive Barrier to Gene Flow
}

\author{
Jeffrey L. Feder, ${ }^{1}$ Scott P. Egan, ${ }^{2}$ and Andrew A. Forbes ${ }^{3}$ \\ ${ }^{1}$ Department of Biological Sciences, University of Notre Dame, Notre Dame, IN 46556, USA \\ ${ }^{2}$ Department of Biological Sciences, Advanced Diagnostics and Therapeutics, Environmental Change Initiative, \\ University of Notre Dame, Notre Dame, IN 46556, USA \\ ${ }^{3}$ Department of Biology, University of Iowa, 434A Biology Building, Iowa City, IA 52242, USA \\ Correspondence should be addressed to Jeffrey L. Feder, feder.2@nd.edu \\ Received 14 August 2011; Accepted 16 November 2011 \\ Academic Editor: Rui Faria
}

Copyright ( $) 2012$ Jeffrey L. Feder et al. This is an open access article distributed under the Creative Commons Attribution License, which permits unrestricted use, distribution, and reproduction in any medium, provided the original work is properly cited.

\begin{abstract}
Habitat choice is an important component of most models of ecologically based speciation, especially when population divergence occurs in the face of gene flow. We examine how organisms choose habitats and ask whether avoidance behavior plays an important role in habitat choice, focusing on host-specific phytophagous insects as model systems. We contend that when a component of habitat choice involves avoidance, there can be repercussions that can have consequences for enhancing the potential for specialization and postzygotic reproductive isolation and, hence, for ecological speciation. We discuss theoretical and empirical reasons for why avoidance behavior has not been fully recognized as a key element in habitat choice and ecological speciation. We present current evidence for habitat avoidance, emphasizing phytophagous insects, and new results for parasitoid wasps consistent with the avoidance hypothesis. We conclude by discussing avenues for further study, including other potential roles for avoidance behavior in speciation related to sexual selection and reinforcement.
\end{abstract}

\section{Introduction}

The last two decades have seen a renewal of interest in the ecological context of speciation [1-5]. This interest has been spawned, in large part, by a greater acceptance that speciation can progress in the face of gene flow [6-10]. Ecological adaptation is a central component of many speciationwith-gene-flow models [8]. Specifically, divergent natural selection imposed by different habitats or environments can serve as an important "extrinsic" barrier to gene flow to initiate speciation [11]. When fitness tradeoffs exist, populations may not always be capable of simultaneously adapting phenotypically and genetically to the contrasting selection pressures imposed by different habitats to be jack-off-alltrades generalists. Consequently, migrants moving between habitats or hybrids formed by mating between individuals from different populations will not thrive compared to resident parental types [12]. Thus, ecological reproductive barriers due to fitness trade-offs can form that, if strong enough, can promote speciation.

Two aspects of ecological adaptation are particularly important for speciation-with-gene-flow. One concerns habitat-related performance traits and the other habitat choice [13-17]. Habitat performance involves traits or genes that increase the survivorship of their progeny in one habitat but have negative fitness consequences in alternative habitats. Such tradeoffs have obvious consequences for reducing effective gene flow between populations due to the reduced fitness of migrants and hybrids, as discussed previously. Questions have been raised as to how common and strong performance tradeoffs are between populations in nature [18-20]. However, instances of strong host plant-related fitness tradeoffs for plant-eating insects have been found [8, 21]. Moreover, it is clear that certain ecological dimensions of habitats will likely impose strong divergent selection pressures. For example, morphological aspects of resource 
processing such as the beaks of birds [22-24], the proboscis length of insects [25], and the pharyngeal gills of fish [26] will not be ideal for all food items and will incur a cost in handling time to effectively use a subset of resources versus others. Also, seasonal differences in resource availability cannot always be bridged by a single life history strategy for a short-lived organism that, for instance, has only a single generation per year [27]. In addition, aspects of pollinator attraction [28] and crypsis in relation to the environment [29] can also have consequences for fitness. Thus, there are reasons to suspect that several ecological dimensions of habitats can impose strong and divergent selection pressures on populations to most effectively utilize them.

The second component of ecological adaptation concerns habitat choice. When habitat-related performance differences exist, individuals that prefer to reside in the habitat to which they are best adapted benefit from a fitness advantage [15]. When habitat choice affects mate choice, then the result is an ecologically based barrier to gene flow. This most easily occurs when individuals mate in their preferred habitats (e.g., if populations form leks or court in different habitats or at different times of the year). The resulting assortative mating can facilitate ecological speciation-withgene-flow because it accentuates selection for performance traits that in turn increase selection for habitat fidelity [1517]. By mating in preferred habitats, individuals that possess traits increasing their survivorship in a particular habitat will tend to mate with other individuals possessing the same suite of ecological adaptations, increasingly favoring those that remain in their "natal" habitats. Thus, positive correlations can evolve between traits affecting habitat choice (e.g., host plant quality decision for oviposition by phytophagous insects) and offspring survival in habitats [30].

Here, we are interested in how organisms choose habitats. Specifically, we ask the question of whether avoidance behavior plays an important role in habitat choice, focusing on host-specific phytophagous insects as model systems. We contend that when a component of habitat choice involves avoidance, there can be repercussions that can have consequences for enhancing the potential for specialization and postzygotic reproductive isolation and, hence, for ecological speciation.

\section{Habitat Preference versus Avoidance}

In general, when we think about how organisms decide to reside in one habitat versus alternatives, we think in terms of positive preference. Specifically, preferences exist that result in an individual deciding to live in one habitat that it likes the best over others. If we think about preferences being affected by some number of genetic loci, then a greater proportion of alleles across these preference genes favoring the acceptance of one habitat versus another would result in an organism being relatively more likely to reside in that habitat [16]. Hybridization between populations with preferences for different habitats will result in offspring of mixed ancestry that will, in the absence of genetic dominance, tend to have no strong preference for either parental habitat and consequently an interest for both habitats. These hybrids could therefore serve as effective bridges or conduits of gene flow between populations in different habitats and impede specialization. For this reason, Mayr [31, 32] argued that the genetics of habitat preference was a problem for ecological speciation-with-gene-flow. The more preference genes that affect habitat choice in the genome, the harder it would be for pure habitat choice for one parental habitat versus another to sort itself out in individuals of mixed ancestry. Thus, it would be difficult for ecological specialization to drive speciation in the face of gene flow unless habitat choice was concentrated in just a few loci of strong effect with consistent dominance interactions for choice of a particular habitat.

Habitat choice may not be solely determined by positive preference, however. It has long been argued that phytophagous insect specialists, for example, use positive cues from hosts and negative cues from nonhost plants when evaluating their environment [33-35]. Consequently, as well as possessing genes to prefer specific habitats, phytophagous insects may also have loci or alleles at certain loci that cause them to avoid nonnatal, alternate habitats.

Theoretical models have been constructed that have considered habitat avoidance as a factor in ecological speciation but these have been restrictive in that they tend to model avoidance additively [36, 37]. However, avoidance (as well as preference) may commonly have nonadditive phenotypic and fitness effects with important consequences for ecological speciation that go beyond the implications of habitat preference. For example, alleles resulting in increased preference for one habitat may have pleiotropic consequences simultaneously increasing an individual's disdain for other nonnatal habitats that do not possess preferred characteristics [17]. Also, if avoidance genes exist, then hybrids possessing alleles to avoid alternate parental habitats may be behaviorally conflicted and accept no habitat. Thus, hybrids could suffer a degree of postzygotic reproductive isolation, being incapable of finding suitable habitats to feed and mate in (i.e., hybrids would incur a degree of behavioral inviability/sterility). Moreover, in contrast to preference genes, the more genes there are that strongly and independently affect avoidance, the stronger the barrier to gene flow between populations, as it would become harder and harder to segregate out a parental behavioral phenotype that would be willing to reside in any one habitat [17]. Thus, rather than the genetics of habitat choice providing a bridge, avoidance could create a greater reproductive chasm fostering ecological speciation-with-gene-flow.

Avoidance could also have consequences for ecological speciation not only occurring in the face of gene flow in sympatry or parapatry but also occurring in allopatry in geographically isolated populations. If the evolution of increased preference has pleiotropic effects that increase avoidance for alternative habitats, then the independent evolution of increased natal habitat choice in allopatry might cause both pre- and postzygotic isolation if populations were ever to come back together in secondary contact. In this case, the evolution of increased preference in allopatry could stem, for example, from selective pressures for individuals to more efficiently and accurately judge variation in their 
natal habitat quality and avoid suboptimal natal resources [38-40]. Alternatively, avoidance could also initially evolve in response to local nonnatal habitats that become significant following secondary contact when these alternate habitats share characteristics in common with other, previously allopatric, nonnative habitats inhabited by a related taxon.

The issue of why habitat avoidance is not a more generally appreciated element of ecological adaptation is a central topic of this paper. We argue that part of the answer may be theoretical and part due to experimental design. For avoidance to cause postzygotic reproductive isolation in sympatry or parapatry invokes the classic theoretical problem that a new mutation causing inviability or sterility cannot establish in the face of gene flow [41]; any new mutation reducing fitness in heterozygotes, including behavioral avoidance incompatibilities in hybrids, should be rapidly selected against and eliminated from populations. In this paper, we propose several ways in which this problem can be alleviated and that avoidance behavior can evolve in the face of gene flow despite negative fitness consequences in hybrids. This includes a discussion on the potential genetic and physiological changes that can result in the evolution of habitat avoidance, focusing on the olfactory system of host plant specific phytophagous insects.

The second problem with avoidance is empirical. Although the hypothesis of habitat avoidance has been articulated, in part, by several leading entomologists including Bernays and Chapman [33], Jermy and Szentesi [42], and Frey and Bush [43], the idea has overall gained only modest experimental traction (see [34]). We suggest that this may stem from studies of habitat use generally not being designed or analyzed with the possibility of avoidance behavior in mind. Rather, most host choice experiments are focused on preference and whether hybrid individuals will accept one parental habitat (or host plant) versus the other. Evidence for avoidance can go undetected or unexamined in such tests. Here, we discuss several studies of insect host plant choice in the literature and new results from a wasp parasitoid Utetes lectoides that are consistent with the evolution of host avoidance. We conclude by examining several aspects of host plant choice studies that may mask the presence of avoidance behavior and suggest that avoidance may be a common component of ecological specialization and speciation, at least for phytophagous insect specialists.

\section{Theoretical Models for Habitat Avoidance}

The basic theoretical issue with habitat avoidance generating behavioral inviability/sterility concerns the following conundrum: how is it possible, if hybrids are unfit, to evolve from the high-fitness genotype of one specialist population (species) to the high-fitness genotype of the other population (species) without passing through a low fitness intermediate? In allopatry, the answer is relatively straight-forward and is attributed to the insights of Bateson, Dobzhansky, and Muller [44-47]. Specifically, hybrid inviability or sterility often arises from between-locus genetic incompatibilities: alleles that function well within species are incompatible with one another when brought together for the first time in the genome of an individual of mixed ancestry ([48] for review). Genetic architectures of this form are known as Dobzhansky-Muller (D-M) incompatibilities and allow populations to evolve reproductive isolation without passage through a fitness-valley that would be opposed by selection. Alleles for preference for the natal habitat that inadvertently cause avoidance to alternative, nonnatal habitats accumulate independently in allopatric populations separated by geographic barriers that preclude migration and, consequently, no negative fitness consequences in hybrids. If these physical barriers happened to dissipate and populations were to come back into secondary contact and interbreed, then hybrids would suffer behavioral inviability/sterility due to possessing alleles causing them to avoid aspects of all suitable parental habitats. Thus, avoidance can easily be envisioned to play an important role in generating ecological reproductive isolation in allopatry.

We note that in allopatry, a similar argument can also be made with respect to mate choice. Sexual selection and assortative mating might involve both a preference for a given trait(s) in mates and avoidance of individuals lacking the trait(s). Hence, avoidance aspects of mate choice can result in both pre- and postzygotic reproductive isolation following secondary contact in a similar manner as ecological habitat choice. Moreover, the same considerations with respect to the number of loci underlying habitat avoidance would apply to mate avoidance; the greater the number of genes that independently affect avoidance, the potentially stronger the reproductive barrier to gene flow. The role of avoidance behavior in sexual selection and assortative mating is an area warranting further theoretical study.

The theoretical difficulty with habitat avoidance therefore rests primarily on whether similar behavioral inviability/sterility barriers can also evolve in sympatry or parapatry in the face of gene flow, as is possible in the absence of migration in allopatry. Here, the argument is that it is not feasible because unlike the situation in allopatry, the negative consequences of a new mutation causing avoidance would be immediately exposed to selection against it in heterozygotes. However, there are reasons why this conventional wisdom may be incorrect. First, parapatric models have shown how new favored mutations that can cause genomic incompatibilities can alternately arise in the nonoverlapping portions of two taxon's ranges experiencing low levels of migration and elevate to high frequencies (e.g., see [49]). When these favored mutations spread into the contact area, hybrids suffer reduced fitness and thus a reproductive barrier to gene flow exists that fosters speciation. Consequently, with certain parapatric distributions of taxa, behavioral habitat inviability/sterility can evolve in a similar manner as in allopatry. But in these circumstances, avoidance behavior is not initially evolving directly in the face of gene flow.

Second, Agrawal et al. [50] in this issue show that when new mutations subject to divergent natural selection also affect intrinsic isolation, either directly or via linkage disequilibrium with other loci, such alleles can overcome gene flow, diverge between populations, and thus result in the evolution of intrinsic isolation. Thus, if divergent 
TABLE 1: Three models for how genetically based behavioral incompatibilities due to conflicting habitat avoidance can evolve during speciation-with-gene-flow that cause postzygotic isolation in hybrids (see Figures 1-3).

Model 1: intermediate null allele $(o)$

Step 1: $a^{+}$state in ancestral population for a habitat choice locus with a recessive null $(o)$ allele also segregating as low a frequency polymorphism that confers no habitat preference.

Step 2: new habitat becomes available and o/o genotypes from ancestral population shift and adapt to novel habitat.

Step 3: new avoidance mutation to ancestral habitat $\left(a^{-}\right)$arises and elevates to high frequency in primarily $o$ null allele initial genetic background of novel habitat population.

Step 4: new avoidance mutation to novel habitat $\left(n^{-}\right)$arises that confers even greater fidelity to ancestarl habitat than $a^{+}$allele and elevates to high frequency in the ancestral habitat population.

Step 5: behavioral inviability/sterility in hybrids when individuals move between novel and ancestral habitat and cross mate producing $n^{-} / a^{-}$heterozygotes at habitat choice locus.

Model 2: epistasis between habitat preference and avoidance loci

Step 1: initial $a^{+}$state exists for ancestral habitat preference at habitat preference locus in ancestral population and initial $n^{-}$state for novel habitat avoidance at habitat avoidance locus.

Step 2: new habitat becomes available and new preference mutation for novel habitat $\left(n^{+}\right)$arises and elevates to high frequency in novel habitat population.

Step 3: new avoidance mutation to ancestral habitat $\left(a^{-}\right)$arises at avoidance locus and elevates to high frequency in novel habitat population because negative effects of $n^{-} / a^{-}$heterozygosity at avoidance locus are not expressed in $n^{+} / n^{+}$genetic background at the preference locus in the novel habitat.

Step 4: behavioral inviability/sterility in hybrids when individuals move between novel and ancestral habitat and cross mate producing $n^{-} / a^{-}$heterozygotes at habitat avoidance locus in $n^{+} / a^{+}$genetic background of hybrids at the preference locus.

Model 3: epistasis between ancestral and novel habitat loci with preference and avoidance alleles

Step 1: initial $a^{+}$state exists for ancestral habitat preference at ancestral habitat choice locus in ancestral population and initial $n^{-}$state for novel habitat avoidance at novel habitat locus.

Step 2: new habitat becomes available and new preference mutation for novel habitat $\left(n^{+}\right)$arises at novel habitat choice locus and elevates to high frequency in novel habitat population.

Step 3: new avoidance mutation to ancestral habitat $\left(a^{-}\right)$arises at ancestral habitat choice locus and elevates to high frequency in $n^{+} / n^{+}$genetic background at the novel habitat locus in the novel habitat population.

Step 4: behavioral inviability/sterility in hybrids when individuals move between novel and ancestral habitat and cross mate producing $a^{+} / a^{-}$heterozygotes at ancestral habitat locus in $n^{+} / n^{-}$genetic background of hybrids at the novel habitat locus.

selection for nonnatal habitat avoidance is strong enough relative to migration and to its deleterious consequences in heterozygote "hybrids", it can evolve in the face of gene flow to differentiate sympatric and parapatric populations. Increased habitat fidelity could be favored to restrict the formation of less fit hybrids, even if it involved a degree of increased behavioral inviability/sterility in individuals of mixed ancestry, provided that the increase in fitness due to pre-zygotic isolation outweighs the postzygotic cost. Indeed, a difficulty with reinforcement models is that with decreased hybridization due to pre-zygotic isolation, the selection pressure for the evolution of further reinforcement decreases [51]. However, if the differential establishment of avoidance alleles in divergent populations increases not only pre-zygotic isolation but also the degree of behavioral inviability/sterility in hybrids, then selection pressures for reinforcement could remain strong even as gene flow levels decrease. The role of avoidance behavior in reinforcement is an area in need of further theoretical analysis.

Third, the divergent selection models of Agrawal et al. [50] in this issue mainly focus on whether a new favorable mutation conferring a fitness advantage in one habitat could establish in the face of gene flow if it directly interacted negatively with other alleles in the prestanding genetic background to cause postzygotic behavioral inviability/sterility. However, much like traditional D-M incompatibilities [41], the evolution of avoidance behavior could involve a stepwise sequence of substitutions of new mutations that each resulted in a minimum amount of reduced fitness in heterozygotes or hybrids until completion of the process. As a consequence, sequential habitat choice models might widen the conditions for divergent ecological selection to generate postzygotic reproductive. We depict three such sequential habitat choice models in Table 1 that involve either intermediate alleles and dominance interactions at a single locus or epistatic interactions between loci to cross through fitness valleys for habitat avoidance to evolve and generate postzygotic isolation.

The first model (see Figure 1 and Table 1) involves multiple substitutions at a single locus affecting habitat choice in which one of the allelic states $(o)$ at the choice gene is a null mutation that does not affect habitat choice. This model is an 


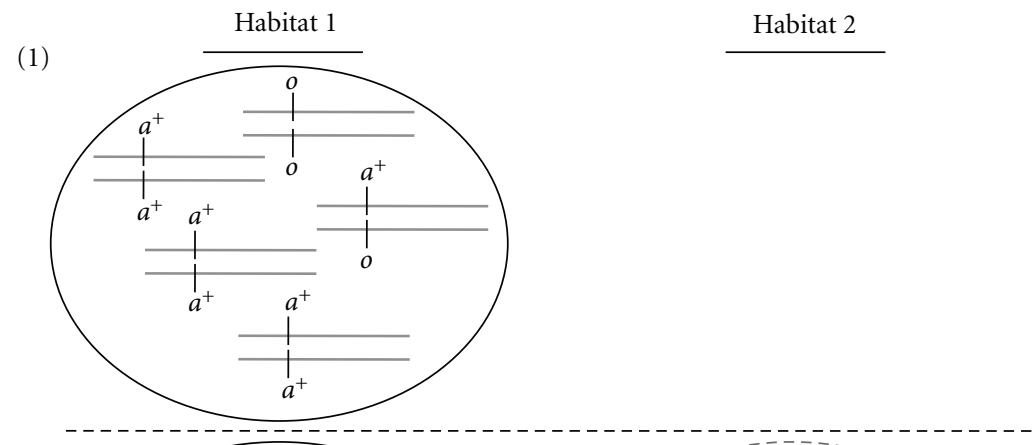

(2)

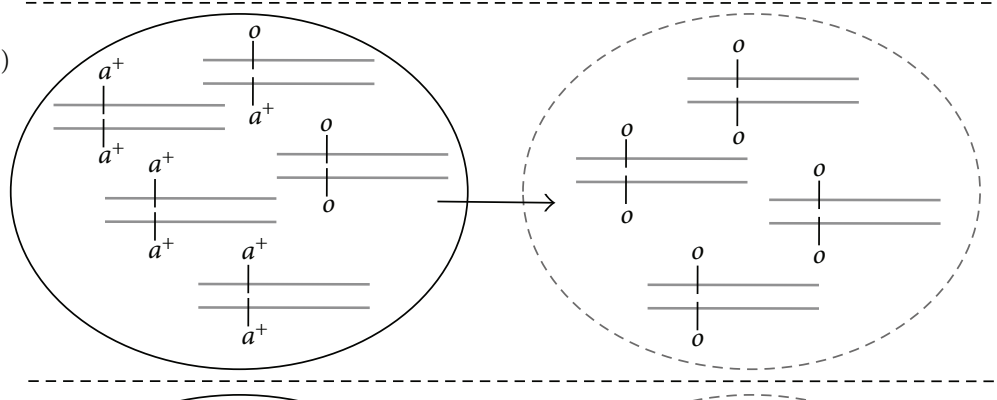

(3)

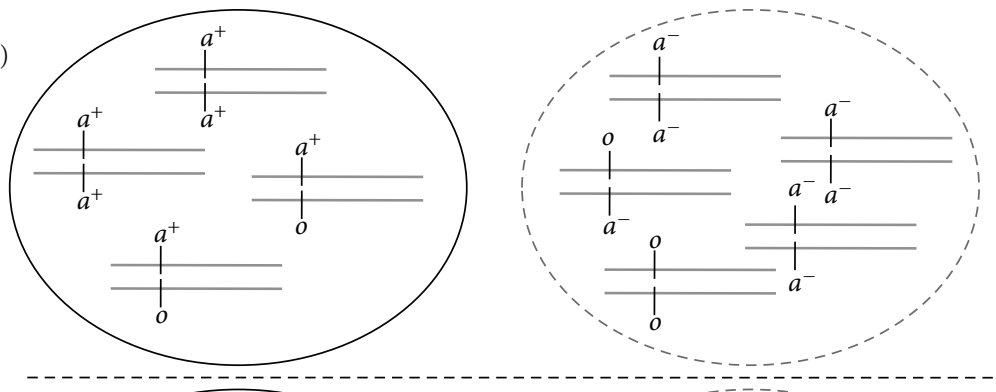

(4)

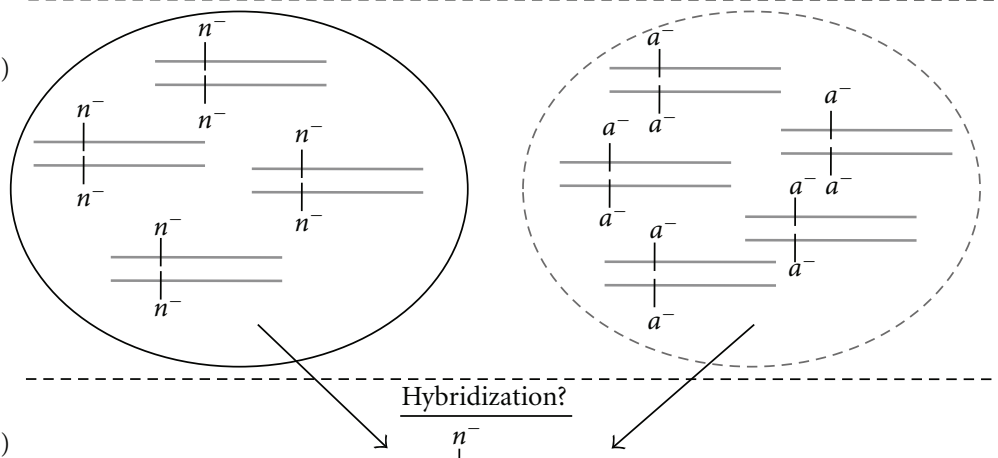

(5)

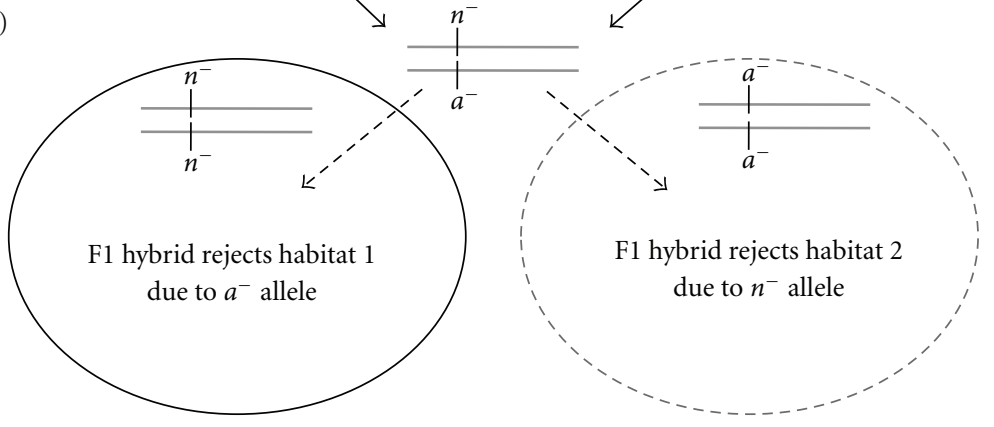

Figure 1: Illustration of model 1 based on intermediate null allele (see Table 1 for model description). Numbered steps of model (1-5) are separated by dashed lines and ordered vertically. Individuals are represented by chromosome pairs as grey bars; avoidance locus is marked by solid black tick mark on grey chromosome. Alleles at avoidance locus are labeled as follows: $a^{+}:$preference for ancestral habitat; $o$ : recessive null allele (i.e., no preference or avoidance); $a^{-}$: avoidance for ancestral habitat; $n^{-}$: avoidance for novel habitat. Arrow depicts shift from ancestral habitat 1 to novel habitat 2 . 
extension of Nylin and Wahlberg's [52] hypothesis that host shifts for phytophagous insects start with a broadening of the host acceptance range (e.g., ovipositing females respond to a wider range of plant cues). Following this initial generalist (oligophagous) phase, sympatric speciation can occur via host race formation or allopatric speciation can occur via the evolution of more specialized local subpopulations $[53,54]$. For example, initially most individuals attacking an ancestral host plant may possess $a^{+}$alleles conferring ancestral host recognition. However, a recessive null $(o)$ allele resulting in no habitat preference may also initially be present in the ancestral population as standing genetic variation (see Step 1 for Model 1 in Figure 1 and Table 1). In the absence of an alternative host, the null allele might have little negative fitness consequences to its bearers and so exists as a low-frequency polymorphism maintained by purifying selection/mutation balance. An alternative, novel habitat then becomes available and is colonized primarily by individuals with the recessive (o) allele (Step 2). After some local (performance-related) adaptation to the novel habitat, a new dominant avoidance allele $\left(a^{-}\right)$can arise and reach high frequency in the novel population to avoid the ancestral habitat where migrants would have lower fitness (Step 3). Following this, if a new mutation for strongly avoiding the novel habitat $\left(n^{-}\right)$happened to arise in the ancestral population, then it could reach high frequency in the ancestral population (Step 4). Rather than being primarily selected against in an $a^{-}$genetic background in which the negative fitness consequences of conflicted host choice would be immediately exposed in heterozygotes, the $n^{-}$allele would mainly be selected for in the ancestral population in an $a^{+}$genetic background. Thus, alternative $a^{-}$and $n^{-}$alleles could come to differentiate populations utilizing novel versus ancestral habitats that adversely interact with each other to decrease hybrid fitness (Step 5).

A second model (see Figure 2 and Table 1) involves two separate loci, one affecting habitat preference and the other habitat avoidance, that epistatically interact. In most genetic backgrounds, heterozygotes for alternate habitat avoidance alleles to the novel and ancestral habitats $\left(n^{-} / a^{-}\right)$at the habitat avoidance locus would have impaired behavior. However, in an $n^{+} / n^{+}$homozygous genetic background for the preference locus causing individuals to orient to the novel habitat (Step 2), the deleterious phenotypic effects of $n^{-} / a^{-}$ heterozygosity at the avoidance locus are not expressed (Step 3 ), providing a pathway to alleviate the maladaptive fitness valley associated with habitat avoidance during a shift to a novel habitat (Step 4).

Finally, a third model (see Figure 3 and Table 1) involves epistatic interactions as in model two, except rather than separate preference and avoidance loci, habitat choice is based on one locus that influences orientation to the ancestral habitat and a second that dictates choice of the novel habitat. The distinction between models 2 and 3 then is that in model 2 a given locus affects either avoidance or preference, but not both behaviors, to alternative habitats. In contrast, in model 3 the different loci are directly tied to cues associated with one habitat or the other (be they olfactory, visual, tactile, or gustatory), with different alleles conferring different avoidance or preference responses to just those habitat specific cues. In the case of model 3 , an initial mutation at the novel habitat locus from $n^{-}$to $n^{+}$ can result in a degree of orientation to the novel host (Step 2 ). In an $n^{+} / n^{+}$genetic background, a new $a^{-}$avoidance mutation to the ancestral host occurs at the ancestral habitat locus which establishes in the novel habitat (Step 3) and is only behaviorally incompatible in hybrids possessing $a^{-}$and $n^{-}$alleles at the ancestral and novel habitat choice genes, respectively (Step 4).

Feder and Forbes [17] theoretically analyzed the second epistasis model through a series of computer simulations in which levels of gene flow, divergent selection, habitat choice, recombination, and hybrid behavioral incompatibility were varied. The results implied that the conditions for habitat avoidance were not overly restrictive under the epistasis scenario and that the evolution of behavioral inviability/sterility in the face of gene flow was possible. More detailed analyses estimating the probabilities of establishment of new avoidance alleles are still needed to definitively assess how likely epistasis model two is for generating behavioral inviability/sterility with gene flow. The computer simulations were based on deterministic models showing that the frequencies of new avoidance alleles would increase due to selection but did not assess how probable this increase would be relative to stochastic loss. Moreover, analyses of the first and third models are still required, although preliminary deterministic simulations suggest that they have similar characteristics as model two (Feder, unpublished data). Consequently, while the evolution of genomic incompatibilities is undoubtedly easier in allopatry than in sympatry or parapatry, there is no strong theoretical impediment to habitat avoidance evolving and causing a degree of hybrid behavioral inviability/sterility.

\section{Physiological Basis for Habitat Avoidance}

A key question with respect to the issue of habitat avoidance is how organisms that are specialized for an ancestral habitat evolve the physiological mechanisms to not only prefer a novel habitat but also avoid their original ancestral habitat. In this regard, it would seem most likely that such a transition, if it evolved in the face of gene flow, would initially involve a large and rapid shift in behavior due to a small number of important alleles or loci, rather than a number of small, quantitative, stepwise changes. If habitat choice involved a large number of small effect genes, then this would imply that a relatively high degree of migration would be occurring between populations during critical early periods of speciation-with-gene-flow. In this case, unless all new mutations for choosing (or avoiding) the novel habitat were dominant and/or habitat-related performance differences were pronounced and genomically wide-spread, it would seem difficult for a number of small effect genes to establish. Moreover, it would make it theoretically more difficult for behavioral inviability/sterility to evolve, as the small advantage in habitat choice conferred by these genes could not be offset by any appreciable negative consequences in hybrids or the new mutations would not establish. Thus, 


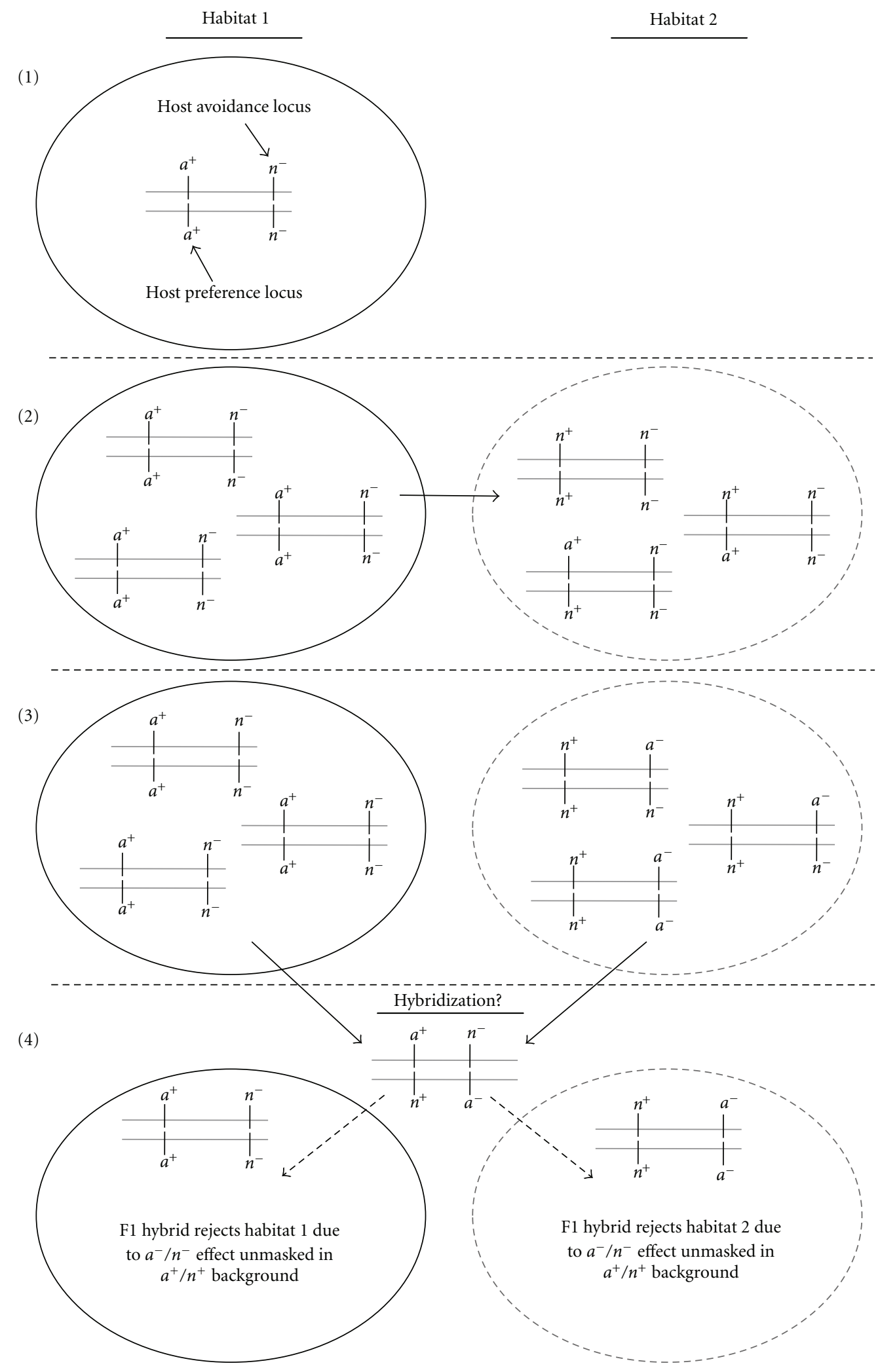

Figure 2: Illustration of model 2 based on epistasis between habitat preference and avoidance loci. Numbered steps of model (1-4) are separated by dashed lines and ordered vertically. Individuals are represented by chromosome pairs as grey bars; preference locus (on left) and avoidance locus (on right) are marked by two pairs of vertical black tick marks on grey chromosomes. Alleles at preference locus are labeled as follows: $a^{+}$: preference for ancestral habitat; $n^{+}:$preference for novel habitat. Alleles at avoidance locus are labeled as follows: $n^{-}$: avoidance for novel habitat; $a^{-}$: avoidance for ancestral habitat. Arrow depicts shift from ancestral habitat 1 to novel habitat 2. 

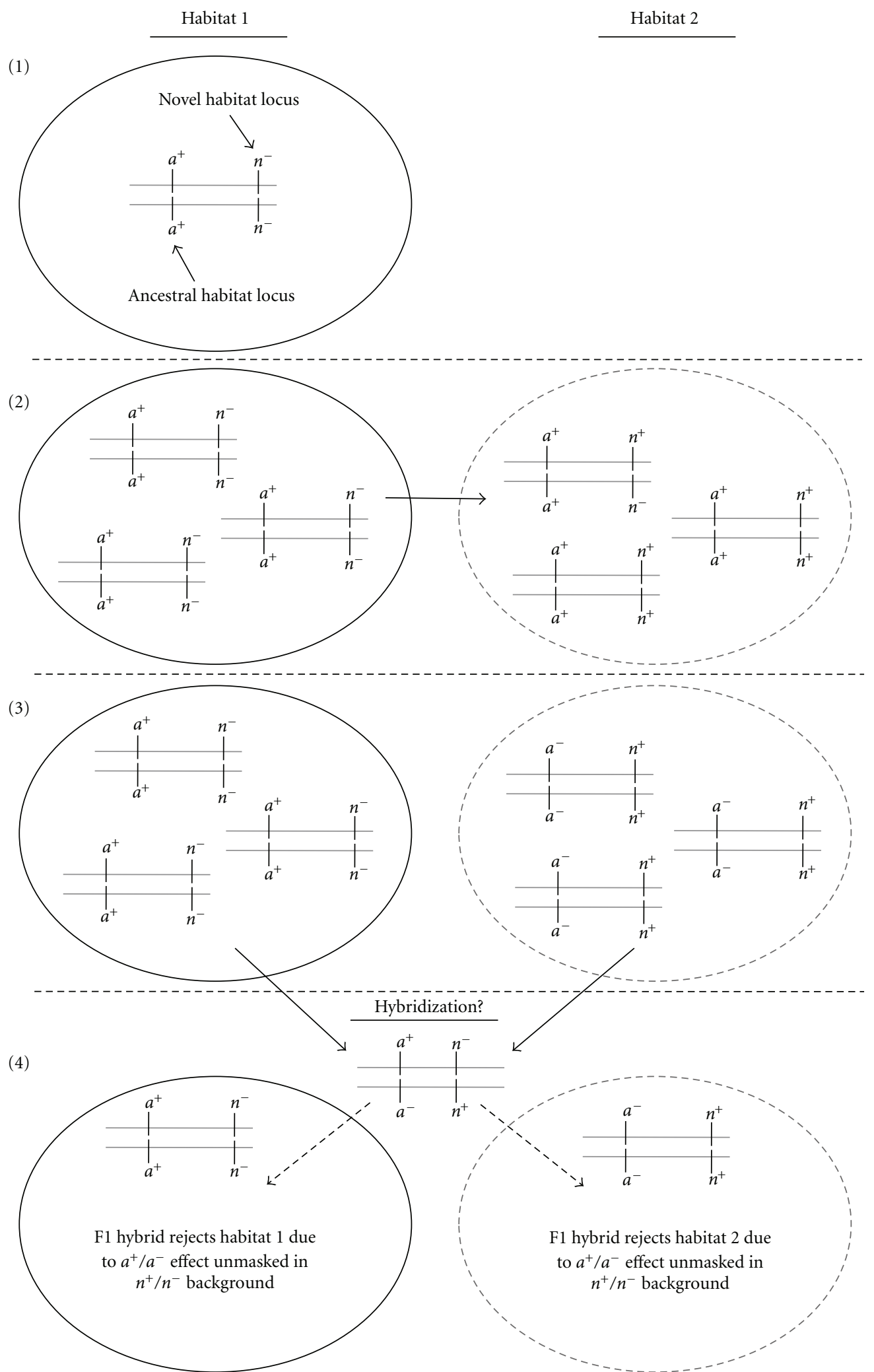

FIGURE 3: Illustration of model 3 based on epistasis between ancestral and novel habitat loci with preference and avoidance alleles. Numbered steps of model (1-4) are separated by dashed lines and ordered vertically. Individuals are represented by chromosome pairs as grey bars; ancestral (on left) and novel (on right) habitat loci are marked by two pairs of vertical black tick marks on grey chromosomes. Alleles at ancestral locus are labeled as follows: $a^{+}$: preference for ancestral habitat; $a^{-}$: avoidance for ancestral habitat. Alleles at novel locus are labeled as follows: $n^{+}$: preference for novel habitat; $n^{-}$: avoidance for novel habitat. Arrow depicts shift from ancestral habitat 1 to novel habitat 2. 
TABLE 2: Changes to olfactory system that can potentially affect the behavioral orientation of insects to plants.

\begin{tabular}{ll}
\hline Genetic change & Effect \\
\hline $\begin{array}{l}\text { Odorant binding-protein } \\
\text { conformation }\end{array}$ & $\begin{array}{l}\text { Determines nonpolar } \\
\text { compounds carried to } \\
\text { dendrite of } \\
\text { chemoreceptor }\end{array}$ \\
$\begin{array}{l}\text { Change in conformation of protein } \\
\text { at receptor site on chemoreceptor }\end{array}$ & $\begin{array}{l}\text { cell to particular } \\
\text { compound }\end{array}$ \\
$\begin{array}{l}\text { Alter numbers of receptor sites for } \\
\text { particular chemical on } \\
\text { chemoreceptor }\end{array}$ & $\begin{array}{l}\text { Alter sensitivity of cell to } \\
\text { particular compound }\end{array}$ \\
$\begin{array}{l}\text { Alter second messenger or } \\
\text { membrane properties of }+ \text { or }-\end{array}$ & $\begin{array}{l}\text { Alter sensitivity of }+ \text { or } \\
\text { chemoreceptor }\end{array}$ \\
$\begin{array}{l}\text { Alter gene expression pattern of } \\
\text { receptor proteins on }+ \text { and }- \text { cells }\end{array}$ & $\begin{array}{l}\text { Switch effect of } \\
\text { stimulation from }+ \text { to }- \\
\text { or vice versa }\end{array}$ \\
$\begin{array}{l}\text { Alter wiring of sense cells or } \\
\text { interneurons }\end{array}$ & $\begin{array}{l}\text { Switch effect of } \\
\text { stimulation from }+ \text { to }- \\
\text { or vice versa } \\
\text { Alter levels of one or more } \\
\text { neuromodulators at synapses } \\
\begin{array}{l}\text { Alter sign of synaptic inputs in path } \\
\text { to controlling center }\end{array}\end{array}$ \\
\hline
\end{tabular}

it would seem that if speciation with-gene-flow is to occur, initial changes in host choice may often involve large effect alleles. Of course, this is not an important consideration in allopatry, where habitat choice genes of small effect could accumulate independently in geographically isolated demes and have large deleterious behavioral consequences in hybrids following secondary contact and gene flow. Regardless, the issue remains of how a new mutation could induce a big (or even small) shift in behavior from a like to dislike (or vice versa).

We illustrate possible mechanisms for generating large behavioral shifts in habitat choice using the olfactory system of phytophagous insects as a model (see Figure 1 in supplementary material available online at doi: $10.1155 / 2012 / 456374$.). We focus on olfaction in insects because it is well-established that many phytophagous insect specialists are highly sensitive to particular compounds [5557] or characteristic mixtures of volatiles $[35,58,59]$ emitted from their host plants. This olfactory sensitivity is normally viewed as an adaptation for host finding, especially when the herbivore displays directed, odor-based anemotaxis over long distances [35]. In addition to being attracted by hostspecific chemicals, specialists also tend to be deterred by nonhost secondary metabolites [33, 34, 42]. This suggests a possible role for olfactory avoidance in host plant choice and the potential for behavioral incompatibilities in hybrids. Moreover, there are more plant-associated insects $(>500,000$ described species) than any other form of Metazoan life, making the issue of host avoidance particularly relevant for understanding the relationship between ecological adaptation and the genesis of biodiversity [60].

The peripheral olfactory system of insects consists of chemosensory neurons present in specialized sensory hairs called sensilla (Supplementary Figure 1) ([71] for review). In many insects, olfactory sensilla are found on two pairs of olfactory organs on the head, the antennae and the maxillary palps. Each olfactory sensillum is innervated by up to four olfactory receptor neurons (ORNs). Odor molecules from the environment pass through pores in the cuticular walls of the sensilla where they become bound to odor binding proteins (OBPs). The OBPs transport the odor molecules to seven-transmembrane bound odorant receptor (OR) proteins that span the cell membranes of the dendrites of ORNs. Individual ORNs express only one or a few ORs of a potential large superfamily of $O R$ genes [72-75]. Drosophila, for example, possess 60 different $O R$ genes in their genomes [76]. Each OR binds to a unique class of molecule or compound, which confers specific odor response properties to the firing of the ORN $[73-75,77]$. Output from the peripheral olfactory system ORNs is sent to two antennal lobes that contain a number of nerve cells organized into glomeruli. In most cases, the innervated axons of ORNs expressing the same OR converge to a single glomerulus in each antennal lobe $[72,78]$. Thus, the number of glomeruli is approximately equal to the number of $O R$ genes an insect possesses. Here, the ORN axons synapse with second-order neurons that project to the higher brain centers in insects: the mushroom body and the lateral horn [79]. The glomeruli are also the locations of local interneuron synapses, which enable the flow of information between glomeruli and likely play roles in organizing the input signal $[79,80]$. It is generally thought that the negative and positive neural inputs are processed in an additive manner in the central nervous system of insects [81], resulting in an insect behaviorally responding to whatever the balance of olfactory input signals is at a particular moment in time [35].

Switches from a positive to negative response to a chemical input signal could conceivably occur due to changes at any one of several points in the olfactory system. (Note that there is a general similarity and deep evolutionary homology in the sensory systems between insects and other multicellular organisms, implying that changes in the insect can have parallels in many other life forms.) We outline a few potential target points in Table 2. In essence, the central component of the argument is that if areas of the insect brain are associated with positive orientation when innervated and others with avoidance, then a shift in behavior can occur through any mechanism that changes (switches) the input signals to these areas. Thus, a change in the expression pattern of OBPs or ORs genes in ORNs can result in an odorant that was formally an attractant (agonist) of behavior becoming a deterrent (antagonist) or vice versa. For example, oviposition site preference is determined by a few loci in the fruit fly, Drosophila sechellia, where an odorant-binding protein gene is involved in the specialization of the fly to the fruit of its host plant, Morinda citrifolia [85]. Similarly, 
a developmental change in the connections of ORN axons to glomeruli or of the secondary order neurons to the higher brain centers would also produce such a transformation. Thus, there are several potential mechanisms in which a new mutation could have a major effect on chemotaxis.

An outstanding issue is still why a phytophagous insect's olfactory system should not be more sophisticated and allow for fine-tuned and subtle host discrimination rather than the general black and white patterns of likes and dislikes that we cite previously. One answer, if our hypothesis is correct, may be that the level of complex decision making in olfactory (and sense) systems is context dependent on the neural capacity of organisms. Bernays [35] has argued that neurons are energetically expensive to operate and develop, as well as to house when body size is an issue. Thus, there may be constraints on how many nerve cells and how large and interconnected many phytophagous insect's brain can be. As a result, many phytophagous insects may be limited to more basic agonistic (likes) versus antagonistic (dislikes) behavioral responses to host plant cues. Such a system can also make sense in how most phytophagous insects probably experience the world. It may not usually be the case that an insect will have to make a choice between two or more different potential host plants simultaneously. Rather, it may be more common in typical spatially heterogeneous environments for an individual to experience a single host at a time and have to decide whether to accept or reject it. Thus, although we do not expect that all insect olfactory responses are black/white in nature, such decision-making system, while perhaps not always optimal, may be a serviceable solution for host choice for many insects given the inherent evolutionary constraints.

\section{Empirical Studies}

Our motivation for considering the role of habitat avoidance in ecological speciation is due, in part, to empirical discoveries in the apple maggot fly, Rhagoletis pomonella, a model system for sympatric speciation via host shifting $[1,86-$ 88]. In particular, the recent shift of the fly from its native and ancestral host hawthorn (Crataegus spp.) to introduced, domesticated apple around 150 years ago in the eastern U.S. is often cited as an example of incipient sympatric speciation in action [8].

Volatile compounds emitted from the surface of ripening fruit have been shown to be the most important long to intermediate range cues used by $R$. pomonella to locate host trees [89]. Once in the tree canopy, flies use both visual and olfactory cues at distances of $\leq 1$ meter to pinpoint the location of fruit for mating and oviposition. Recently, we found that not only are the ancestral hawthorn and recently formed apple-infesting host races of $R$. pomonella attracted to volatile compounds emitted from their respective natalhost fruit [90], but they also tend to avoid the nonnatal volatiles of the alternate fruit $[64,65]$. Because $R$. pomonella flies mate only on or near the fruit of their respective host plants [91, 92], fruit odor discrimination results directly in differential mate choice.
Most interestingly, F1 hybrids between apple and hawthorn flies failed to orient to the odor of either apple or hawthorn fruit in flight tunnel assays, consistent with behavioral conflicts generated by fruit volatile avoidance [82]. In addition, behavioral responses to parental fruit volatiles were restored in a fair proportion of F2 and backcross hybrids (35$60 \%$ ), suggesting that only a few major genetic differences underlie the phenotype [93]. This does not mean that a large number of genes do not affect olfaction and host choice. Rather, it suggests that only that a few changes in a relatively small number of genes might generate behavioral incompatibilities. Field tests still need to be conducted to determine if the compromised chemosensory system of nonresponding hybrids results in greatly reduced fitness in nature, although it is difficult to envision how these flies do not suffer at least some disadvantage. We also caution that the Rhagoletis results do not directly confirm that conflicting avoidance behavior is the cause for the lack of behavioral response of F1 hybrid flies in flight tunnel assays. It is possible that the disrupted olfactory system of hybrids could be a pleiotropic consequence of developmental incompatibilities due to divergent selection on other host-related traits, such as differences in the timing of diapause that adapts apple and hawthorn flies to variation in when their respective host plants fruit $[27,94,95]$. It also remains to be determined what specific aspect of the Rhagoletis olfactory system is impaired in hybrids. Initial studies suggested that the peripheral olfactory system was altered in hybrids, as a far higher percentage of single cell ORNs responded to multiple classes of host plant volatiles in hybrids than in parental apple and hawthorn flies [96]. This implied that these ORNs were misexpressing multiple $O R$ genes that could disrupt behavior. However, comparison between F2 and backcross flies that both responded and failed to respond to apple and hawthorn fruit volatiles in the flight tunnel showed no differences in ORN firing patterns to specific compounds; both behavioral responders and nonresponders displayed the same altered ORN patterns that F1 hybrids did [97]. Thus, altered $O R$ gene expression could be incidental or subtly contribute to loss of behavioral orientation in F1 hybrids but may not be the only or prime cause for the disruption. In a similar manner, altered ORN patterns do not distinguish whether habitat avoidance or a pleiotropic effect of a more general developmental incompatibility forms the basis for loss of behavior in hybrids. Additional work needs to be done to clarify these issues.

\section{Additional Evidence and Problems}

To determine how general habitat avoidance may be and how common disrupted host choice behavior may be in hybrids, we surveyed the plant-associated insect literature for potential examples. Although not exhaustive, we found 10 examples consistent with avoidance behavior (Table 3). These include insects across several orders, including Coleoptera, Hymenoptera, Hemiptera, and Diptera. A Y-tube or alternative olfactometer apparatus is often the method used to assess avoidance, although no-choice field and laboratory-based 
TABLE 3: Studies showing evidence consistent with insect avoidance of nonhost plants and/or their volatiles.

\begin{tabular}{|c|c|c|c|c|}
\hline Species & Order; Family & Assessment method(s) & $\begin{array}{l}\text { Electrophysio. } \\
\text { response nonhost } \\
\text { volatiles? }\end{array}$ & Reference \\
\hline Dryocosmus kuriphilus & Hymenoptera: Cynipidae & Y-tube olfactometer & Yes & {$[61]$} \\
\hline Sitophilus zeamais & Coleoptera: Curculionidae & Four-way olfactometer & $?$ & {$[62]$} \\
\hline Brevicoryne brassicae & Hemiptera: Aphididae & Y-tube olfactometer & Yes & {$[63]$} \\
\hline Aphis fabae & Hemiptera: Aphididae & Y-tube olfactometer & Yes & {$[63]$} \\
\hline Rhagoletis pomonella & Diptera: Tephritidae & $\begin{array}{l}\text { Field test; no-choice } \\
\text { flight tunnel }\end{array}$ & Yes & {$[64,65]$} \\
\hline Diachasma alloeum & Hymenoptera: Braconidae & Y-tube olfactometer & Yes & {$[66]$} \\
\hline Pityogenes chalcographus & Coleoptera: Curculionidae & Field test & $?$ & {$[67]$} \\
\hline Tomicus piniperda & Coleoptera: Curculionidae & Field test & Yes & {$[68]$} \\
\hline Hylurgops palliatus & Coleoptera: Curculionidae & Field test & $?$ & {$[68]$} \\
\hline Heliothrips haemorrhoidalis & Thysanoptera: Thripidae & unknown & $?$ & {$[70]$} \\
\hline
\end{tabular}

tests have been used, as well. In many cases, electroantennal readings were made in addition to behavioral tests to determine whether nonhost volatiles induced electrophysiological activity. In all cases, experiments were designed to explicitly test for avoidance behavior.

A difficulty with assessing avoidance behavior stems from the nature of the experimental assays of behavior. A particular problem is that host studies are often done in choice experiments in which insects are given plant material from alternative hosts in a confined area and the relative proportions of time they choose to use the plants used as a measure of preference. The difficulty here can be twofold. First, as discussed previously, insects usually do not have to directly choose between alternate hosts in nature. Rather, more often than not, host use comes down to acceptance or rejection of a given plant. Hence, no choice experiments are a better test for preference behavior, providing that the subjects are not overly stressed by their physiological condition or circumstances to accept lower ranking hosts, regardless of plant quality. This may be especially important when testing for host avoidance. Having plants too close together in an arena in a choice test can result in mixed sensory cues confounding insects with signals not often experienced in the wild. For example, in Rhagoletis, the addition of nonnatal compounds to a natal fruit volatile blend (apple or hawthorn) does not just result in behavioral indifference but often an active avoidance of apple and hawthorn flies to the mixed blend $[64,65]$. In choice situations between natal versus nonnatal blends, overall capture rates of apple and hawthorn flies can fall and, of great importance, discrimination for a fly's natal blend declines [98]. It is likely that in these instances the one meter distance between natal versus nonnatal blends in these trials was not sufficient to preclude volatile plume mixing. Flies therefore interpreted both volatile blends as nonnatal and displayed decreased orientation to the natal versus nonnatal blend than in tests conducted using the natal blend versus a blank control. One must therefore be careful in interpreting the results from choice studies.
The choice trials for Rhagoletis also highlight a second problem in testing for avoidance behavior: the use of proportional host acceptance rather than absolute values to assess discrimination. If one were to analyze the relative proportions of acceptance of natal versus nonnatal volatiles as a comparative metric in host studies, it could appear that host discrimination goes down in multiple choice experiments versus no choice tests. The key is to estimate and compare absolute acceptance behaviors in no choice trials, however, as well as the time it takes for acceptance. If not, evidence for host avoidance could be masked and underestimated. For example, it may be that $50 \%$ of the time a hybrid insect may choose one plant versus another in a choice test, suggesting no preference or avoidance on a relative scale. However, it may be that hybrids come to reside on plants and less often than their parents do. Thus, although the hybrids are not showing a preference difference, on an absolute scale they are making host acceptance decisions less often than parental individuals, which could reflect the existence of conflicting avoidance behavior.

We also surveyed the literature for plant-associated insects to look for behavioral host choice dysfunction in hybrids consistent with avoidance alleles reducing hybrid fitness (Table 4). Here, the current evidence mainly comes from Rhagoletis, a leaf-feeding beetle (Neochlamisus bebbianae) and a hymenopteran parasitoid (Leptopilina boulardi). In all cases, F1 hybrids express a reduced ability to orient or respond to parental host plants or host-plant volatiles.

\section{New Empirical Data}

As an example of how one might implement a test for habitat avoidance, we recently conducted a preliminary Ytube olfactory study testing for nonnatal host avoidance for a braconid parasitoid, Utetes lectoides, attacking the fruit fly Rhagoletis zephyria in snowberry fruit in the western USA Domesticated apples were brought by settlers to the Pacific Northwest region of the USA in the last 200 years and it is believed that $R$. pomonella was introduced via larval 
TABle 4: Studies presenting data consistent with habitat avoidance alleles causing problems in hybrids. Each cross-generated hybrids displaying reduced response relative to parents in habitat choice. Host plant or locality information is in parentheses.

\begin{tabular}{|c|c|c|c|}
\hline Taxon & Hybrid cross & Reduced hybrid response & Reference \\
\hline Rhagoletis fruit flies & $\begin{array}{l}\text { R. pomonella }(\text { apple }) \times R \text {. pomonella } \\
(\text { haw })\end{array}$ & Upwind flight to host odor & {$[82]$} \\
\hline Rhagoletis fruit flies & $\begin{array}{l}\text { R. pomonella }(\text { apple }) \times R \text {. nr. pomonella } \\
(\text { dogwood) }\end{array}$ & Upwind flight to host odor & {$[82]$} \\
\hline Rhagoletis fruit flies & $\begin{array}{l}\text { R. pomonella }(\text { haw }) \times R \text {. nr. pomonella } \\
(\text { dogwood })\end{array}$ & Upwind flight to host odor & {$[82]$} \\
\hline Rhagoletis fruit flies & $\begin{array}{l}R \text {. pomonella }(\text { apple }) \times R \text {. mendax } \\
\text { (blueberry) }\end{array}$ & Electroantennogram to fruit odor & {$[43]$} \\
\hline Neochlamisus leaf beetles & $\begin{array}{l}\text { N. bebbianae }(\text { maple }) \times N \text {. bebbianae } \\
\text { (willow) }\end{array}$ & Time spent on foraging on parental host plants & $\begin{array}{l}\text { Egan and Funk, } \\
\text { unpubl.; [83] }\end{array}$ \\
\hline Leptopilina parasitoids & $\begin{array}{l}\text { L. boulardi }(\text { Nasrallah }) \times \text { L. boulardi } \\
(\text { Brazzaville })\end{array}$ & Probing response to fruit odor ${ }^{1}$ & {$[84]$} \\
\hline
\end{tabular}

${ }^{1}$ Only in one direction of the F1 hybrid cross (Nasrallah female $\times$ Brazzaville male).

infested apples within the last 50 years. We hypothesized that snowberry fly origin populations of $U$. lectoides in the western USA might have recently evolved to avoid the volatile odors emanating from introduced apple fruit. A glass Y-tube with each arm connected to a filtered air source was set on a flat surface with an attractive light source at the end of the tube where the arms intersect. All wasps were individually tested for behavioral orientation in the system by assessing whether they turn into the left-hand arm, or the right-hand arm, or whether they fail to reach the y-intersection. This establishes a baseline level of response due to the system itself, in the absence of fruit volatiles. An odor (here, emitted from the surface of apple or snowberry fruit) can then be added to just one randomly selected arm of the tube, and wasps reintroduced to the system. Avoidance (or preference) is measured by the change in response to the arm of the tube containing the odor. Preliminary results for $U$. lectoides were consistent with the nonnatal habitat avoidance hypothesis. Only 1 of 12 wasps attacking snowberry wasps that were tested $(8.3 \%)$ oriented to the arm of the Y-tube containing apple fruit volatiles versus a blank, odorless arm compared to the established $42 \%$ baseline control response when both arms were blank $\left(\chi^{2}=4.9, P=0.026,1 \mathrm{df}\right)$. Additional testing with larger sample sizes is needed to confirm the pilot study results and to better establish the extent to which $U$. lectoides orients to snowberry volatiles ( 4 of $9=44 \%$ of wasps did in our initial study). Nevertheless, this example demonstrates avoidance and how one might easily test for such behavior.

\section{Conclusions}

In this paper, we have investigated the idea that avoidance behavior may play a significant role in how organisms select the habitats they reside in (see also [99] for a complementary review of habitat choice). We contend that in addition to positively orienting to certain critical cues in their natal habitat, organisms also actively reject alternative habitats that contain nonnatal elements. If true, then the evolution of avoidance behavior can have important implications for the evolution of ecologically based reproductive isolation that go beyond the pre-zygotic barriers resulting from preference alone. Specifically, contrasting avoidance behaviors can cause host choice conflicts in hybrids, resulting in postzygotic reproductive isolation. Similar thinking about behavioral avoidance could also apply to sexual selection and reinforcement, widening the consequences of these processes for postzygotic isolation during speciation.

We discussed the current theoretical and empirical evidence for habitat avoidance, focusing on phytophagous insects as a model system. In general there is evidence supporting habitat avoidance, but more work needs to be done to verify that avoidance conflicts in hybrids directly cause F1 inviability and sterility in finding habitats and mates. In allopatry, there would seem to be no theoretical difficulty for selection on habitat choice to generate behavioral, as well as developmental conflicts, in hybrids following secondary contact. Although more difficult in sympatry or parapatry, we outlined how it is also possible to evolve habitat avoidance that causes postzygotic isolation in the face of gene flow. More theoretical work needs to be done in this area to produce estimates of how probable it is for new mutations having differing effects on avoidance and behavioral incompatibility to establish between diverging populations. Experimental work also clearly shows that insects use certain chemical cues from nonhosts to avoid these plants. However, it must still be clearly shown that reduced host choice response in hybrids is due to conflicting avoidance behaviors rather than to the pleiotropic consequences of developmental incompatibilities for other traits affecting sensory systems involved in habitat choice. Moreover, detailed neural physiology and genetic studies are needed to determine and map how avoidance evolves and how habitat choice is disrupted in hybrids. Analysis of habitat choice, and avoidance behavior in particular, is still in its early stages but is an intriguing area of theoretical and empirical study linking ecology adaptation and speciation with physiology, development, and genetics. Our current 
knowledge, while incomplete, suggests that there may be great ecological significance and evolutionary potential for the often anthropomorphically ill-viewed trait of disdain.

\section{Acknowledgments}

This work was supported by grants from the NSF to J. L. Feder and A. A. Forbes and the USDA to J. L. Feder, as well as support from the Notre Dame AD\&T and ECI to S. P. Egan. The authors would like to thank Dietmar Schwarz for supplying U. lectoides wasps for Y-tube experiments, Stuart Baird for discussions and ideas about the potential role of avoidance behavior in sexual selection and reinforcement, and Roger Butlin, Stewart Berlocher, and two anonymous reviewers for helpful comments on improving the manuscript.

\section{References}

[1] J. L. Feder, C. A. Chilcote, and G. L. Bush, "Genetic differentiation between sympatric host races of the apple maggot fly Rhagoletis pomonella," Nature, vol. 336, no. 6194, pp. 61-64, 1988.

[2] D. Schluter, "Ecological causes of speciation," in Endless Forms: Species and Speciation, D. J. Howard and S. H. Berlocher, Eds., pp. 114-129, Oxford University Press, Oxford, UK, 1998.

[3] H. D. Rundle and P. Nosil, "Ecological speciation," Ecology Letters, vol. 8, no. 3, pp. 336-352, 2005.

[4] D. J. Funk, P. Nosil, and W. J. Etges, "Ecological divergence exhibits consistently positive associations with reproductive isolation across disparate taxa," Proceedings of the National Academy of Sciences of the United States of America, vol. 103, no. 9, pp. 3209-3213, 2006.

[5] A. P. Hendry, P. Nosil, and L. H. Rieseberg, "The speed of ecological speciation," Functional Ecology, vol. 21, no. 3, pp. 455-464, 2007.

[6] G. L. Bush, "Sympatric speciation in animals: new wine in old bottles," Trends in Ecology and Evolution, vol. 9, no. 8, pp. 285288, 1994.

[7] S. Via, "Sympatric speciation in animals: the ugly duckling grows up," Trends in Ecology and Evolution, vol. 16, no. 7, pp. 381-390, 2001.

[8] S. H. Berlocher and J. L. Feder, "Sympatric speciation in phytophagous insects: moving beyond controversy?" Annual Review of Entomology, vol. 47, pp. 773-815, 2002.

[9] M. Drès and J. Mallet, "Host races in plant-feeding insects and their importance in sympatric speciation," Philosophical Transactions of the Royal Society B, vol. 357, no. 1420, pp. 471492, 2002.

[10] D. I. Bolnick and B. M. Fitzpatrick, "Sympatric speciation: theory and empirical data," Annual Review of Ecology, Evolution, and Systematics, vol. 38, pp. 459-487, 2007.

[11] D. Schluter, "Evidence for ecological speciation and its alternative," Science, vol. 323, no. 5915, pp. 737-741, 2009.

[12] P. Nosil, "Divergent host plant adaptation and reproductive isolation between ecotypes of Timema cristinae walking sticks," American Naturalist, vol. 169, no. 2, pp. 151-162, 2007.

[13] J. Maynard Smith, "Sympatric speciation," American Naturalist, vol. 100, pp. 637-650, 1966.

[14] J. Felsenstein, "Homage to Santa Rosalia, or why are there so few kinds of animals?" Evolution, vol. 35, pp. 124-138, 1981.
[15] S. R. Diehl and G. L. Bush, "The role of habitat preference in adaptation and speciation," in Speciation and Its Consequences, D. Otte and J. Endler, Eds., Sinauer Associates, Sunderland, Mass, USA, 1989.

[16] J. D. Fry, "Multilocus models of sympatric speciation: bush versus rice versus felsenstein," Evolution, vol. 57, no. 8, pp. 1735-1746, 2003.

[17] J. L. Feder and A. A. Forbes, "Habitat avoidance and speciation for phytophagous insect specialists," Functional Ecology, vol. 21, no. 3, pp. 585-597, 2007.

[18] R. Butlin, "A new approach to sympatric speciation," Trends in Ecology and Evolution, vol. 2, no. 10, pp. 310-311, 1987.

[19] D. J. Futuyma and T. E. Philippi, "Genetic variation and covariation in responses to host plants by Alsophila pometaria ( Lepidoptera: Geometridae)," Evolution, vol. 41, no. 2, pp. 269279, 1987.

[20] J. D. Fry, "The evolution of host specialization: are trade-offs overrated?” American Naturalist, vol. 148, pp. S84-S107, 1996.

[21] J. Scheirs, K. Jordaens, and L. De Bruyn, "Have genetic tradeoffs in host use been overlooked in arthropods?" Evolutionary Ecology, vol. 19, no. 6, pp. 551-561, 2005.

[22] P. R. Grant and B. R. Grant, "Unpredictable evolution in a 30year study of Darwin's finches," Science, vol. 296, no. 5568, pp. 707-711, 2002.

[23] T. L. Parchman and C. W. Benkman, "Diversifying coevolution between crossbills and black spruce on Newfoundland," Evolution, vol. 56, no. 8, pp. 1663-1672, 2002.

[24] C. W. Benkman, "Divergent selection drives the adaptive radiation of crossbills," Evolution, vol. 57, no. 5, pp. 11761181, 2003.

[25] S. P. Carroll and C. Boyd, "Host race radiation in the soapberry bug: natural history with the history," Evolution, vol. 46, no. 4, pp. 1052-1069, 1992.

[26] J. J. Willacker, F. A. Von Hippel, P. R. Wilton, and K. M. Walton, "Classification of threespine stickleback along the benthic-limnetic axis," Biological Journal of the Linnean Society, vol. 101, no. 3, pp. 595-608, 2010.

[27] J. L. Feder and K. E. Filchak, "It's about time: the evidence for host plant-mediated selection in the apple maggot fly, Rhagoletis pomonella, and its implications for fitness tradeoffs in phytophagous insects," Entomologia Experimentalis et Applicata, vol. 91, no. 1, pp. 211-225, 1999.

[28] J. Ramsey, H. D. Bradshaw, and D. W. Schemske, "Components of reproductive isolation between the monkeyflowers Mimulus lewisii and M. cardinalis (Phrymaceae)," Evolution, vol. 57, no. 7, pp. 1520-1534, 2003.

[29] P. Nosil and B. J. Crespi, "Experimental evidence that predation promotes divergence in adaptive radiation," Proceedings of the National Academy of Sciences of the United States of America, vol. 103, no. 24, pp. 9090-9095, 2006.

[30] S. Gripenberg, P. J. Mayhew, M. Parnell, and T. Roslin, "A meta-analysis of preference-performance relationships in phytophagous insects," Ecology Letters, vol. 13, no. 3, pp. 383393, 2010.

[31] E. Mayr, "Ecological factors in speciation," Evolution, vol. 1, pp. 263-288, 1947.

[32] E. Mayr, Animal Species and Evolution, Harvard University Press, Harvard, Mass, USA, 1963.

[33] E. A. Bernays and R. F. Chapman, "The evolution of deterrent responses in plant feeding insects," in Perspectives in Chemoreceptors and Behavior, R. F. Chapman, E. A. Bernays, and J. G. Stoffolano, Eds., pp. 159-173, Springer, New York, NY, USA, 1987. 
[34] E. A. Bernays, S. Oppenheim, R. F. Chapman, H. Kwon, and F. Gould, "Taste sensitivity of insect herbivores to deterrents is greater in specialists than in generalists: a behavioral test of the hypothesis with two closely related caterpillars," Journal of Chemical Ecology, vol. 26, no. 2, pp. 547-563, 2000.

[35] E. A. Bernays, "Neural limitations in phytophagous insects: implications for diet breadth and evolution of host affiliation," Annual Review of Entomology, vol. 46, pp. 703-727, 2001.

[36] C. Castillo-Chavez, S. A. Levin, and F. Gould, "Physiological and behavioral adaptation to varying environments: a mathematical model," Evolution, vol. 42, no. 5, pp. 986-994, 1988.

[37] M. D. Rausher, "The evolution of habitat preference: avoidance and adaptation," in Evolution of Insect Pests: Patterns of Variation, K. C. Kim and B. A. McPheron, Eds., pp. 259-283, Wiley, New York, NY, USA, 1993.

[38] N. Janz and S. Nylin, "The role of female search behaviour in determining host plant range in plant feeding insects: a test of the information processing hypothesis," Proceedings of the Royal Society B, vol. 264, no. 1382, pp. 701-707, 1997.

[39] S. P. Egan and D. J. Funk, "Individual advantages to ecological specialization: insights on cognitive constraints from three conspecific taxa," Proceedings of the Royal Society B, vol. 273, no. 1588, pp. 843-848, 2006.

[40] H. D. Rundle and J. W. Boughman, "Behavioral ecology and speciation," in Evolutionary Behavioral Ecology, D. F. Westneat and C. W. Fox, Eds., Oxford University Press, Oxford, UK, 2010.

[41] J. A. Coyne and H. A. Orr, Speciation, Sinauer Associates, Inc., Sunderland, Mass, USA, 2004.

[42] T. Jermy and A. Szentesi, "The role of inhibitory stimuli in the choice of oviposition site by phytophagous insects," Entomologia Experimentalis et Applicata, vol. 24, no. 3, pp. 458471, 1978.

[43] J. E. Frey and G. L. Bush, "Impaired host odor perception in hybrids between the sibling species Rhagoletis pomonella and R. mendax," Entomologia Experimentalis et Applicata, vol. 80, no. 1, pp. 163-165, 1996.

[44] W. Bateson, "Heredity and variation in modern lights," in Darwin and Modern Science, A. C. Seward, Ed., pp. 85-101, Cambridge, UK, Cambridge University Press, 1909.

[45] T. Dobzhansky, Genetics and the Origin of Species, Columbia University Press, New York, NY, USA, 1st edition, 1937.

[46] H. J. Muller, "Bearing of the Drosophila work on systematics," in The New Systematics, J. Huxley, Ed., pp. 185-268, Oxford, UK, Oxford University Press, 1940.

[47] H. J. Muller, "Isolating mechanisms, evolution, and temerature," Biology Symposium, vol. 6, pp. 71-125, 1942.

[48] S. Gavrilets, Fitness Landscapes and the Origin of Species, Princeton University Press, Princeton, NJ, USA, 2004.

[49] A. S. Kondrashov, "Accumulation of Dobzhansky-Muller incompatibilities within a spatially structured population," Evolution, vol. 57, no. 1, pp. 151-153, 2003.

[50] A. F. Agrawal, J. L. Feder, and P. Nosil, "Ecological divergence and the origins of intrinsic postmating isolation with gene flow," International Journal of Ecology, vol. 2011, Article ID 435357, 15 pages, 2011.

[51] A. R. Templeton, "Mechanisms of speciation-a population genetic approach," Annual Review of Ecology and Systematics, vol. 12, pp. 32-48, 1981.

[52] S. Nylin and N. Wahlberg, "Does plasticity drive speciation? Host-plant shifts and diversification in nymphaline butterflies (Lepidoptera: Nymphalidae) during the tertiary," Biological Journal of the Linnean Society, vol. 94, no. 1, pp. 115-130, 2008.
[53] N. Janz, S. Nylin, and N. Wahlberg, "Diversity begets diversity: host expansions and the diversification of plant-feeding insects," BMC Evolutionary Biology, vol. 6, article 4, 2006.

[54] E. Weingartner, N. Wahlberg, and S. Nylin, "Dynamics of host plant use and species diversity in Polygonia butterflies (Nymphalidae)," Journal of Evolutionary Biology, vol. 19, no. 2, pp. 483-491, 2006.

[55] P. M. Guerin and E. Städler, "Host odour perception in three phytophagous Diptera: a comparative study," in Proceedings of the 5th International Symposium on Insect-Plant Relationships, pp. 95-106, Pudoc, Wageningen, The Netherlands, 1982.

[56] E. Thibout, J. Auger, and C. Lecomte, "Host plant chemicals responsible for attraction and oviposition in Acrolepiopsis assectella," in Proceedings of the 5th International Symposium on Insect-Plant Relationships, pp. 107-116, Pudoc, Wageningen, The Netherlands, 1982.

[57] E. Bartlet, M. M. Blight, P. Lane, and I. H. Williams, "The responses of the cabbage seed weevil Ceutorhynchus assimilis to volatile compounds from oilseed rape in a linear track olfactometer," Entomologia Experimentalis et Applicata, vol. 85, no. 3, pp. 257-262, 1997.

[58] J. H. Visser, "Host odor perception in phytophagous insects," Annual Review of Entomology, vol. 31, pp. 121-144, 1986.

[59] C. R. Roseland, M. B. Bates, R. B. Carlson, and C. Y. Oseto, "Discrimination of sunflower volatiles by the red sunflower seed weevil," Entomologia Experimentalis et Applicata, vol. 62, no. 2, pp. 99-106, 1992.

[60] V. Novotny, P. Drozd, S. E. Miller et al., "Why are there so many species of herbivorous insects in tropical rainforests?" Science, vol. 313, no. 5790, pp. 1115-1118, 2006.

[61] G. S. Germinara, A. De Cristofaro, and G. Rotundo, "Chemical cues for host location by the chestnut gall wasp, Dryocosmus kuriphilus," Journal of Chemical Ecology, vol. 37, no. 1, pp. 4956, 2011.

[62] D. A. Ukeh, M. A. Birkett, T. J. A. Bruce, E. J. Allan, J. A. Pickett, and A. Jennifer Mordue, "Behavioural responses of the maize weevil, Sitophilus zeamais, to host (stored-grain) and non-host plant volatiles," Pest Management Science, vol. 66, no. 1, pp. 44-50, 2010.

[63] S. F. Nottingham, J. Hardie, G. W. Dawson et al., "Behavioral and electrophysiological responses of Aphids to host and nonhost plant volatiles," Journal of Chemical Ecology, vol. 17, no. 6, pp. 1231-1242, 1991.

[64] A. A. Forbes, J. Fisher, and J. L. Feder, "Habitat avoidance: overlooking an important aspect of host-specific mating and sympatric speciation?" Evolution, vol. 59, no. 7, pp. 15521559, 2005.

[65] C. Linn, S. Nojima, and W. Roelofs, "Antagonist effects of nonhost fruit volatiles on discrimination of host fruit by Rhagoletis flies infesting apple (Malus pumila), hawthorn (Crataegus spp.), and flowering dogwood (Cornus florida)," Entomologia Experimentalis et Applicata, vol. 114, no. 2, pp. 97-105, 2005.

[66] A. A. Forbes, T. H. Q. Powell, L. L. Stelinski, J. J. Smith, and J. L. Feder, "Sequential sympatric speciation across trophic levels," Science, vol. 323, no. 5915, pp. 776-779, 2009.

[67] J. A. Byers, Q.-H. Zhang, F. Schlyter, and G. Birgersson, "Volatiles from nonhost birch trees inhibit pheromone response in spruce bark beetles," Naturwissenschaften, vol. 85, no. 11, pp. 557-561, 1998.

[68] L. M. Schroeder, "Olfactory recognition of nonhosts aspen and birch by conifer bark beetles Tomicus piniperda and Hylurgops palliatus," Journal of Chemical Ecology, vol. 18, no. 9, pp. 15831593, 1992. 
[69] F. Schlyter, Q.-H. Zhang, P. Anderson et al., "Electrophysiological and behavioural responses of Tomicus piniperda and Tomicus minor (Coleoptera: Scolytidae) to non-host leaf and bark volatiles," Canadian Entomologist, vol. 132, no. 6, pp. 965-981, 2000.

[70] A. S. Scott Brown, Interactions of thrips and their control agents on host plants within a glasshouse containing a diverse collection of plant species, $\mathrm{PhD}$ dissertation, Birkbeck College, University of London, 2002.

[71] A. Dahanukar, E. A. Hallem, and J. R. Carlson, "Insect chemoreception," Current Opinion in Neurobiology, vol. 15, no. 4, pp. 423-430, 2005.

[72] L. B. Vosshall, A. M. Wong, and R. Axel, "An olfactory sensory map in the fly brain," Cell, vol. 102, no. 2, pp. 147-159, 2000.

[73] A. A. Dobritsa, W. Van Der Goes Van Naters, C. G. Warr, R. A. Steinbrecht, and J. R. Carlson, "Integrating the molecular and cellular basis of odor coding in the Drosophila antenna," Neuron, vol. 37, no. 5, pp. 827-841, 2003.

[74] T. Elmore, R. Ignell, J. R. Carlson, and D. P. Smith, “Targeted mutation of a Drosophila odor receptor defines receptor requirement in a novel class of sensillum," Journal of Neuroscience, vol. 23, no. 30, pp. 9906-9912, 2003.

[75] A. L. Goldman, W. Van Der Goes Van Naters, D. Lessing, C. G. Warr, and J. R. Carlson, "Coexpression of two functional odor receptors in one neuron," Neuron, vol. 45, no. 5, pp. 661-666, 2005.

[76] H. M. Robertson, C. G. Warr, and J. R. Carlson, "Molecular evolution of the insect chemoreceptor gene superfamily in Drosophila melanogaster," Proceedings of the National Academy of Sciences of the United States of America, vol. 100, no. 24, pp. 14537-14542, 2003.

[77] E. A. Hallem, M. G. Ho, and J. R. Carlson, "The molecular basis of odor coding in the Drosophila antenna," Cell, vol. 117, no. 7, pp. 965-979, 2004.

[78] Q. Gao, B. Yuan, and A. Chess, "Convergent projections of Drosophila olfactory neurons to specific glomeruli in the antennal lobe," Nature Neuroscience, vol. 3, no. 8, pp. 780-785, 2000.

[79] R. F. Stocker, "The organization of the chemosensory system in Drosophila melanogaster: a review," Cell and Tissue Research, vol. 275, no. 1, pp. 3-26, 1994.

[80] R. F. Stocker, M. C. Lienhard, A. Borst, and K. F. Fischbach, "Neuronal architecture of the antennal lobe in Drosophila melanogaster," Cell and Tissue Research, vol. 262, no. 1, pp. 934, 1990.

[81] L. M. Schoonhoven, T. Jermy, and J. A. A. Van Loon, InsectPlant Biology, Chapman and Hall, London, UK, 1998.

[82] C. E. Linn, H. R. Dambroski, J. L. Feder, S. H. Berlocher, S. Nojima, and W. L. Roelofs, "Postzygotic isolating factor in sympatric speciation in Rhagoletis flies: reduced response of hybrids to parental host-fruit odors," Proceedings of the National Academy of Sciences of the United States of America, vol. 101, no. 51, pp. 17753-17758, 2004.

[83] S. P. Egan, Ecological speciation in Neochlamisus bebbianae leaf beetles: The role of postmating isolation and the genetic basis of host use traits, PhD dissertation, Vanderbilt University, 2010.

[84] E. Campan, A. Couty, Y. Carton, M. H. Pham-Delègue, and L. Kaiser, "Variability and genetic components of innate fruit odour recognition in a parasitoid of Drosophila," Physiological Entomology, vol. 27, no. 3, pp. 243-250, 2002.

[85] T. Matsuo, S. Sugaya, J. Yasukawa, T. Aigaki, and Y. Fuyama, "Odorant-binding proteins OBP57d and OBP57e affect taste perception and host-plant preference in Drosophila sechellia," PLoS Biology, vol. 5, no. 5, article e118, 2007.

[86] G. L. Bush, "The taxonomy, cytology, and evolution of the genus Rhagoletis in North America (Diptera, Tephritidae),", Bulletin of the Museum of Comparative Zoology, vol. 134, pp. 431-562, 1966.

[87] G. L. Bush, "Sympatric host race formation and speciation in frugivorous flies of the genus Rhagoletis (Diptera; Tephritidae)," Evolution, vol. 23, pp. 237-251, 1969.

[88] B. A. McPheron, D. C. Smith, and S. H. Berlocher, "Genetic differences between host races of Rhagoletis pomonella," Nature, vol. 336, no. 6194, pp. 64-66, 1988.

[89] R. J. Prokopy and B. D. Roitberg, "Foraging behavior of true fruit flies," American Scientist, vol. 72, pp. 41-49, 1984.

[90] C. Linn, J. L. Feder, S. Nojima, H. R. Dambroski, S. H. Berlocher, and W. Roelofs, "Fruit odor discrimination and sympatric host race formation in Rhagoletis," Proceedings of the National Academy of Sciences of the United States of America, vol. 100, no. 20, pp. 11490-11493, 2003.

[91] R. J. Prokopy, E. W. Bennett, and G. L. Bush, "Mating behavior in Rhagoletis pomonella (Diptera: Tephritidae)-I. Site of assembly," Canadian Entomologist, vol. 103, pp. 1405-1409, 1971.

[92] R. J. Prokopy, E. W. Bennett, and G. L. Bush, "Mating behavior in Rhagoletis pomonella (Diptera: Tephritidae)_II. Temporal organization," Canadian Entomologist, vol. 104, pp. 97-104, 1972.

[93] H. R. Dambroski, C. Linn Jr., S. H. Berlocher, A. A. Forbes, W. Roelofs, and J. L. Feder, "The genetic basis for fruit odor discrimination in Rhagoletis flies and its significance for sympatric host shifts," Evolution, vol. 59, no. 9, pp. 1953-1964, 2005.

[94] J. L. Feder, T. A. Hunt, and L. Bush, "The effects of climate, host plant phenology and host fidelity on the genetics of apple and hawthorn infesting races of Rhagoletis pomonella," Entomologia Experimentalis et Applicata, vol. 69, no. 2, pp. 117-135, 1993.

[95] K. E. Filchak, J. B. Roethele, and J. L. Feder, "Natural selection and sympatric divergence in the apple maggot Rhagoletis pomonella," Nature, vol. 407, no. 6805, pp. 739-742, 2000.

[96] S. B. Olsson, C. E. Linn, A. Michel et al., "Receptor expression and sympatric speciation: unique olfactory receptor neuron responses in F1 hybrid Rhagoletis populations," Journal of Experimental Biology, vol. 209, no. 19, pp. 3729-3741, 2006.

[97] S. B. Olsson, C. E. Linn, J. L. Feder et al., "Comparing peripheral olfactory coding with host preference in the Rhagoletis species complex," Chemical Senses, vol. 34, no. 1, pp. 37-48, 2009.

[98] A. A. Forbes and J. L. Feder, "Divergent preferences of Rhagoletis pomonella host races for olfactory and visual fruit cues," Entomologia Experimentalis et Applicata, vol. 119, no. 2, pp. 121-127, 2006.

[99] S. E. Webster, J. Galindo, J. W. Grahame, and R. K. Butlin, "Habitat choice and speciation," International Journal of Ecology. In press. 

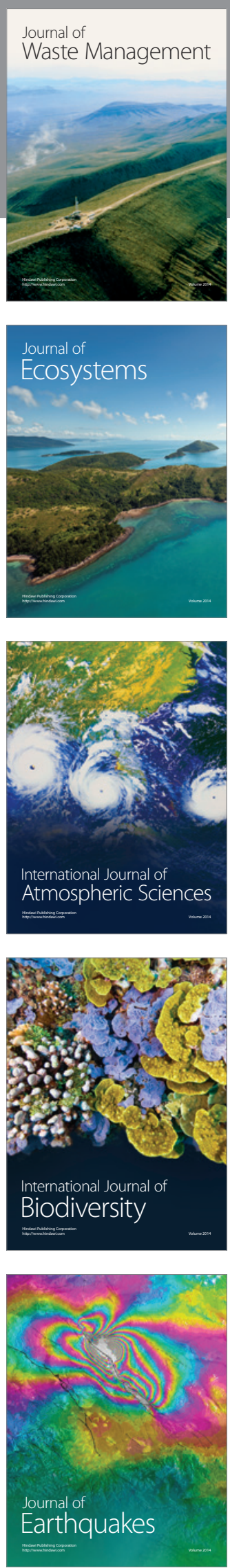
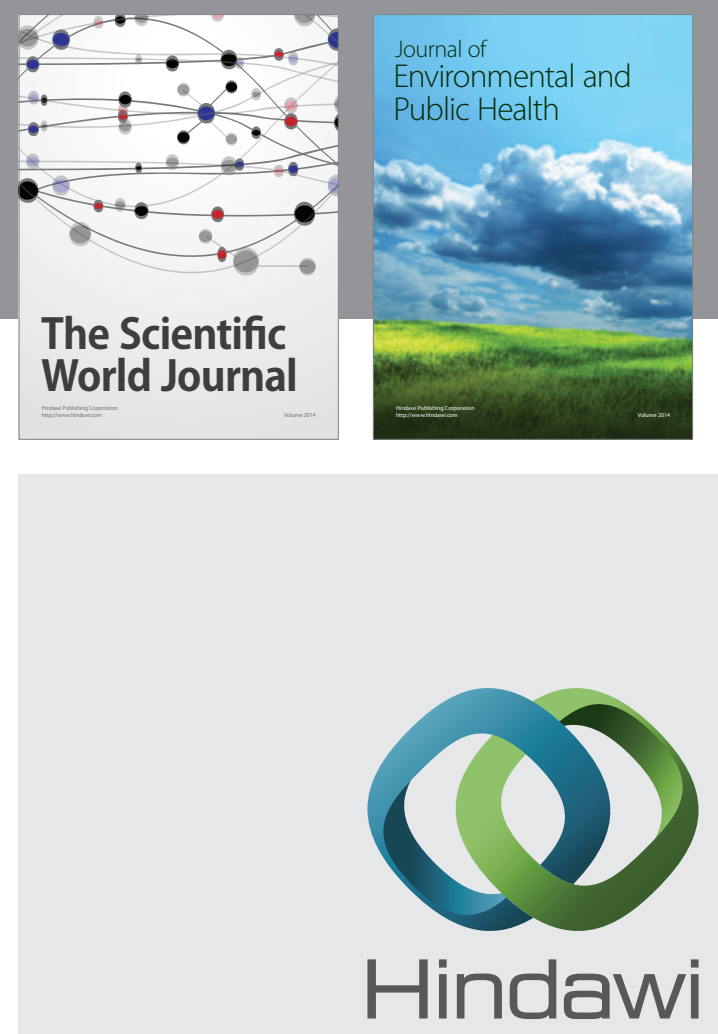

Submit your manuscripts at

http://www.hindawi.com
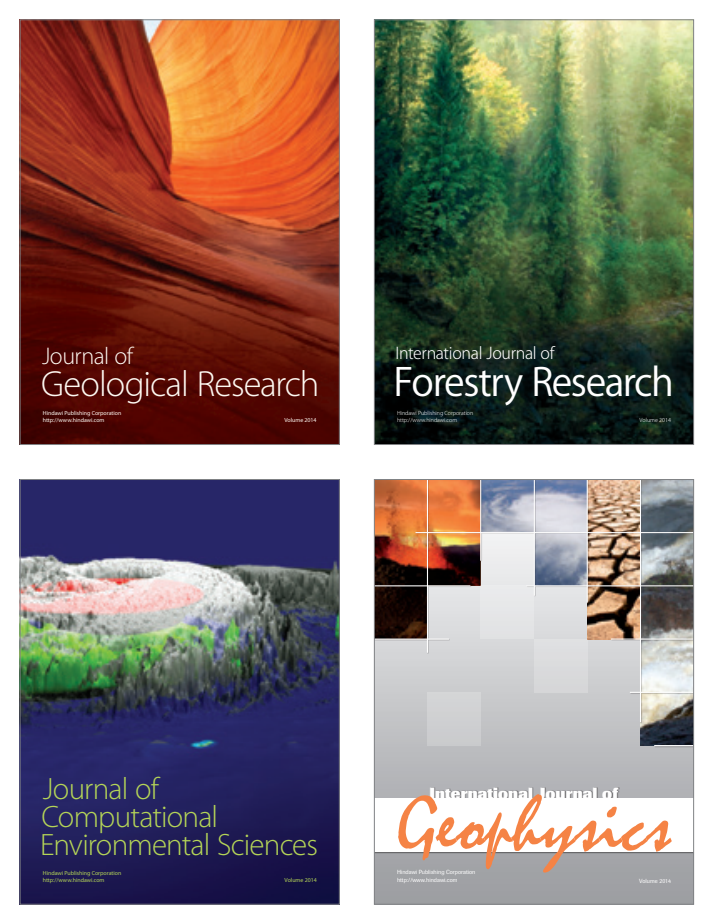
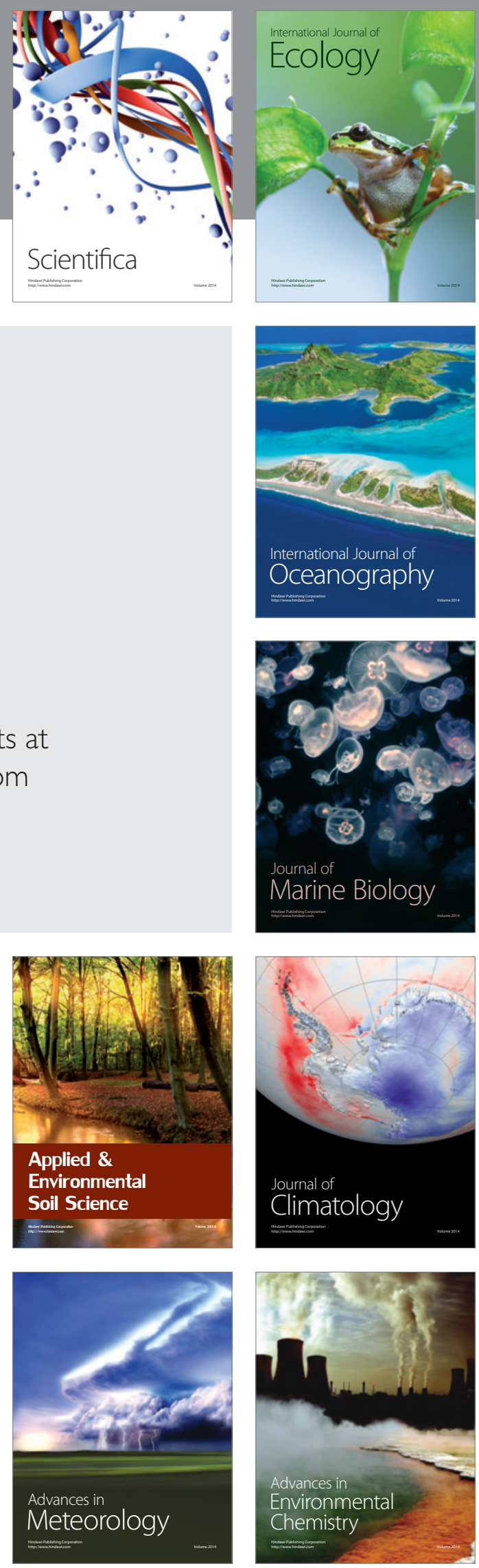